\title{
Erratum to: Solving the Flagpole Problem
}

\author{
Alexander Gebharter ${ }^{1}$
}

\section{Erratum to: J Gen Philos Sci (2013) 44:63-67 DOI 10.1007/s10838-013-9208-6}

The original publication of Alexander Gebharter's "Solving the flagpole problem" (in vol. 44 , no. 1, 2013) contains two typos.

In step 3 of the SGS algorithm presented on p. 65 there appears a ' $Y$ ' instead of a ' $\mathrm{Z}$ ' twice. In particular, step 3 of the SGS algorithm should read as follows: "For all $X, Y, Z \in V$ : If $X-Y-Z$ (or $X \rightarrow Y-Z$ ) and $X$ and $Z$ are non-adjacent (not $X-Z$ ), then orient $X-Y-Z$ (and accordingly $X \rightarrow Y-Z$ ) as $X \rightarrow Y \leftarrow Z$ in the graph resulting from step 2 if and only if $X$ and $Z$ are probabilistically dependent conditional on every subset $M$ of $\backslash\{X, Z\}$ with $Y \in M$."

The online version of the original article can be found under doi:10.1007/s10838-013-9208-6.

Alexander Gebharter

alexander.gebharter@phil.hhu.de

1 Düsseldorf Center for Logic and Philosophy of Science (DCLPS), Heinrich-Heine-University Düsseldorf, 40225 Düsseldorf, Germany 